\title{
GEOPHYSICS AT THE
}

\section{UNIVERSITY OF AUCKLAND}

A. C. Kibblewhite*

\section{Introduction}

Over the last twenty five years the Department of Physics at the University of Auckland has grown from a small group into an organisation of considerable size and stature. Under the guidance first of Professor Burbidge and then of Professor Brown the Department has developed a comprehensive course structure at the undergraduate and graduate levels and established a high reputation widely recognised today. In spite of the difficulties facing all pioneers in University education in those early years, these men were also able to foster a research programme capable of giving substance to all courses, particularly to those offered at the graduate level. With their interest and enthusiasm as the driving force, research into nuclear physics, the field of their choice, increased steadily in scope, and today the Department of Physics boasts an impressive array of sophisticated equipment housed in its Nuclear Physics Laboratories.

However, even in the early days not all the Department's activities were in the nuclear field. Although somewhat overshadowed by the activities in nuclear physics, other research programmes and associated courses have been steadily developing. Significant among these have been those of Professor Kreielsheimer in atmospheric physics, Professor Sagar in ultrasonics and Professor Whale, Drs. Storey and Titheridge in the physics of the upper atmosphere, partciularly in ionospheric physics. With the main Departmental commitment in the nuclear field, there has been only minimal support available for these other activities, and yet these programmes have gradually expanded and thrived. It was at least in part a recognition of the success of this group, that led to the creation of the Chair of Geophysics in Auckland in 1968. However, other influences were also at work. The University of Auckland was not unaware of the general national requirement for the development of geophysics within the University curriculum, and as early as 1965 had considered proposals to create a Department of Geophysics. The new Chair is thus also a recognition of this wider need. It is nevertheless a tribute to these early workers in geophysics that the new chair of Geophysics was created within the Department of Physics. The new appointee was to be responsible for the coordination of all the "nonnuclear" activities within the Department and the development of geophysics in Auckland in a manner best serving the interests of the subject.

*Professor of Geophysics, University of Auckland 
Plans for the development of geophysics in Auckland have been formulated as a result of discussions within the Department and with other interested groups. For instance, a close liaison is, and will be, maintained with the Department of Geology. Views have been exchanged with Professor Evison who became the first Professor of Geophysics in the country when he was appointed to victoria University in 1967. His guidance and advice is naturally invaluable. profitable discussions have also been held with the Directors of the Geophysics Division of the Department of Scientific and Industrial Research, of the New Zealand Oceanographic Institute, of the Naval Research Laboratory, of the Auckland Division of the Geological Survey, representatives of the Ministry of Defence, and visiting geophysicists from overseas Universities. We are aware that modifications to our present plans will be appropriate and necessary from time to time to meet changing circumstances, and sufficient flexibility will be retained to make these changes easy to implement, particularly in our early years.

\section{Courses in Geophysics}

In considering a sensible course structure in geophysics the question arises whether the subject can be developed satisfactorily within the established departmental course systems. A qualified geophysicist should be versed to varying degrees in physics, chemistry, geology, mathematics and engineering and often in aspects of these subjects which find no place within the limitations of orthodox university courses. To provide the optimum type of course will ultimately require the establishment of a separate Department of Geophysics in which the appropriate balanced academic diet can be introduced at the beginning of the undergraduate course. This problem is of course not peculiar to geophysics and a number of major disciplines engineering, medicine and architecture to name a few, are tending more and more to provide their own courses in chemistry, physics and mathematics. Those aspects of these fundamental scientific disciplines which are of particular relevance to the parent course, are developed often at the expense of traditionally classical material.

At this stage of its development at Auckland, however, geophysics is appropriately and comfortably placed in the bosom of Department of Physics, the discipline from which it arose, even though this places natural restrictions on the type of course which can be contemplated. The scope and content of the normal physics course being what it is, it is impossible to add additional material, without excluding something else of equal merit. It is inevitable therefore that most of the geophysics teaching will be at the graduate level, but as it is highly desirable that some material be introduced at the undergraduate level. this has been done. This material is deserving of a place in its own right in any normal physics course, but becomes even more appropriate with post-graduate course in geophysics being available within the Department.

As the subject is too broad for all aspects to be covered even in a Department of Geophysics, the question naturally arises as to what 
parts of the subject we should develop first here at the University of Auckland. For the following reasons it seems appropriate to center our interest in Auckland initially on those aspects of geophysics related to the atmosphere and the oceans.

First the Department is already active in research activities which properly lie within these fields.

Secondly, two research establishments specialising in these fields are sited close to the campus, and the possibility exists for the development of a productive and stimulating scientific environment in the fields of atmospheric and marine geophysics.

Our University-sponsored Radio Research Center is the research organisation involved with upper atmosphere physics. It enjoys an international reputation in ionospheric physics and the close association it already has with the Department can be profitably extended to the ultimate benefit of both groups. The Naval Research Laboratory, which has a vital interest in marine geophysics, is also close enough to the University campus, for close co-operation to be possible. It is one of the biggest scientific units in New Zealand and like the Radio Research Centre enjoys an international reputation. When one considers the limited total effort that is currently being mounted in New Zealand in the oceanographic field, the value of this association with a government research group is apparent.

Thirdly, if Auckland University tends to concentrate on atmospheric and marine geophysics, courses and research so orientated will better complement the activities at the Victoria University. Although Victoria caters for most aspects of geophysics, it is probably true to say that their main interests are in the geophysics of the solid earth. This does not mean that there will be no overlap of courses, but with our national resources being limited, it is a pleasing consequence that the two university geophysics groups within the country complement each another so well.

\section{Undergraduate Courses}

Since the study of geophysics must be based on a sound foundation of the basic sciences, the instruction in geophysics under the present circumstances must be mainly at the graduate level. However, the desirability of some undergraduate courses is recognised, and a course to provide a general introduction to geophysics is currently being given as part of Physics IIIA. This course contains some aspects of the subject in which the Department will not initially specialise at the graduate level, but it will help provide a balanced physics course for those not advancing in the subject, and will prepare to some degree, those students who wish to continue their studies in our own Geology Department or move to Wellington and advance in solid earth geophysics in their Honours year. Arrangements are being made to offer an additional course in marine geophysics as part of the physics IIIB unit. 
The need for other specialised courses for those students whose main interests are in subjects such as Zoology and Botany, apart from Geology, is also recognised. Such courses will aim to give a treatment of those aspects of geophysics which are pertinent to these disciplines. One trial course has been given this year and others will be planned and extended as required.

\section{Graduate Courses}

The courses planned for the graduate level are designed to provide advanced instruction in all those fields of geophysical research being prosecuted within the Department. The significant research projects, both existing and planned, are summarised in the following section, and in support of these specific topics, courses will be available in geomagnetism, ionospheric physics, physics of the lower atmosphere including meteorology, marine geophysics and physical oceanography, and geophysical data acquisition and analysis. This list will be added to as the number of students grows.

Post graduate courses will be aimed at a treatment of a specific aspect of a subject at an advanced level. In developing these it is intended to supplement the courses offered by the staff of the Department with others presented by specialists in given fields of study.

\section{Research Facilities}

Although the special function of a university is to teach, this function can be performed well only in the sort of environment producec by a thriving research activity. This is particularly so if, as in our case, the bulk of the teaching is to take place at the graduate level. Any geophysics group has an outstanding opportunity to provide this research environment, because of New Zealand's unique geographical position on the Earth. New Zealand lies in an almost central position in the extensive ocean areas of the southern hemisphere and is thus in a favoured position for the investigation of many global geophysical phenomena. This fact, together with the country's marked seismicity. its system of geological faults, its volcanic and geothermal activity, its surrounding oceans and complex sea-bed morphology, makes New Zealand a natural laboratory for the pursuit of research into most branches of geophysics.

The Department of Physics already possesses facilities which enable research to be pursued in a number of geophysical fields, in addition to nuclear physics for which it is renowned. These facilities include fine mechanical and electronic workshops, and an excellent team of supporting technical staff. The Department is also fortunate in that the University already sponsors two research organizations pertinent to atmospheric and marine geophysics. The Radio Research centre, which was until recently part of the Department of Physics, operates an excellent field station at Ardmore. Many graduate students have 
presented Master's and Doctorate theses based on ionospheric research carried on at the Centre. More recently the facilities of the Marine Research Laboratory at Leigh have been used to initiate a range of oceanographic studies. In the past the Leigh laboratory has been concerned solely with marine biology, but the introduction of physical oceanography and underwater acoustics has been welcomed by the marine. biologists. All involved see that many advantages will accrue from the close association of the two disciplines and discussions have already been held to explore the areas where measurements of physical oceanographic parameters will tie in with the biological studies at present in progress.

However, our teaching and research programmes in marine geophysics will be restricted unless we can obtain regular access to shipping time. We hope indeed that the Royal New Zealand Navy will be sympathetic to these needs. Over the past fifteen years the Naval Board has given outstanding support to all forms of scientific endeavour in New Zealand, but in no field has this been more marked than in the marine sciences. Besides providing sea transport for all types of scientific expeditions, the Royal New Zealand Navy has made many weeks of shipping time available for the prosecution of marine research programmes. The recent Royal Society Expedition by H.M.N.Z.S. ENDEAVOUR, to mark Captain Cook's bicentenary, is an example of such support. There is no reason to believe that New Zealand Naval authorities will be any less sympathetic to marine research in the future. We are confident therefore that we can expect to develop courses in marine geophysics and oceanography, particularly if our work in this field brings us into close contact with the Naval Research Laboratory.

\section{Current and Future Research Programmes in Geophysics}

The most significant research projects under way at present, or being initiated within the Department, are listed below:-

Atmospheric electricity and cloud physics

At about the time Benjamin Franklin obtained sparks from his lightning conductor under disturbed weather conditions, it was also established that even during fine weather an electric field exists in the air above the Earth's surface. The analysis of the direction of this field points to the presence of a negative charge on the earth and a positive one in the atmosphere above. As the electrical conductivity of air. which is the result of the presence of both positive and negative charges. should tend to neutralise the earth's negative charge in a very short time, the persistence of the negative charge presents one of the most important problems of atmospheric electricity.

Since 1963 continuous recording of the electric field, air-earth current density, and positive and negative atmospheric conductivities 
has been carried out in Auckland. The electric field has been measured using an agrimeter, a radioactive probe and, since June 1969 a field mill. The conductivities are measured with Gerdien condensers, while the current density electrode consists of about one square meter of wire gauze. Specific measurements are also being carried out to examine the relationship between the fine weather electric field, the positive and negative conductivities and the current flowing into a horizontal wire antenna in the atmosphere. To facilitate this project a 16 channel data recording system has been designed and built. Each channel is independent of all the others and may be set to have any sampling interval from $21 / 2$ seconds up to one hour. The sensitivity of each channel is one millivolt and the useful range $-1 \mathrm{v}$. to $+1 \mathrm{v}$. The data is collected on punched paper tape.

The mobility spectra of small atmospheric ions are also being studied. The electric currents involved are typically of the order studied. The electric currents involved are typically of the order of $10^{-15}$ amps and are integrated for about 25 secs before being measured with a vibrating capacitor electrometer. When the measuring technique has been established the variation of spectra with time of day, height above the ground and meteorological conditions will be investigated.

Another fundamental problem receiving attention concerns the manner in which rain drops acquire their electric charge. An attempt is being made to measure the total current associated with a given quantity of rain water and also to measure the quantity of charge associated with individual rain drops.

In the course of the study of the earth's electric field it has been established that the maintenance of the negative charge on the earth is intimately connected with the world-wide thunderstorm activity and it appears that thunderstorms are the principal generators of the Earth's electric field. The study of atmospheric electricity has thus led to a study of the phenomenon of lightning. Besides its fundamental scientific interest to the meteorologist and the atmospheric physicist, lightning is also of vital concern to the electrical engineer. Local lightning activity forms a hazard to high voltage transmission lines in that strikes to conductors or pylons can cause damage to equipment. These studies have, therefore, a definite social and economic implicatior

Lightning counters used to date do not distinguish between cloud and ground flashes and hence given misleading data. One significant objective of our studies has been the development of a simple lightring counter which will register ground flashes only within a reasonably well defined area. This counter operates on a new method involving the measurement of gaps in the radio-noise at frequencies around $10 \mathrm{MHz}$. A simplified version has attracted considerable interest among workers overseas and the Department already has several requests for the construction and supply of such units. At the moment two of these ground stroke counters are in operation - one in Socorro. New Mexico, and the other here in Auckland. 
Besides the obvious significance to us in New Zealand, the results of these studies in atmospheric physics have a much wider interest by virtue of the fact that global considerations make observations in the Southern Hemisphere essential to a complete understanding of the phenomenon of atmospheric electricity. Our Auckland station, along with similar stations all over the world, communicates the results obtained to an international coliecting center in Leningrad.

In all these activities the Department enjoys the valuable cooperation of the New Zealand Meteorological Service. This association, coupled with overseas links, ensures the continuation of a stimulating research programme in this field. Most of these activities have been directed and brought to their present status by Professor K.S. Kreielsheimer. Although he has recently retired, his advice will be available in the future. We expect that much of the study of lightning will be carried on by Mr J.R. Clegg, who is currently on sabbatical leave at the New Mexico Institute of Mining and Technology at Socorro.

A recent addition to the Department is Dr. C.D. Stow from the University of Manchester Institute of Science and Technology, England. His experience and background will add significantly to our strength in atmospheric physics. His interests include the electrification of snow storms, sand storms and volcano plumes but his main field of activity is associated with thunder storm electrification and the micro physics of cloud particle interactions. It is hoped to mount laboratory and field studies to investigate these phenomena and also to develop measurement techniques to enable more precise information to be obtained than has so far been possible. Through his international reputation we hope to foster cooperative programmes with universities in Australia, Japan, the United States and Great Britian.

Physical Oceanography at Leigh

A programme of ocean acoustics which commenced in 1967 under a research contract with Professor F.H. Sagar and the Naval Research Laboratory, and which was based on the use of the Laboratory's vessel R.N.Z.F.A. TUI, came to a sudden and unexpected halt with the decommissioning of this ship at the end of 1967. The programme has been recently transferred to the University's Marine Laboratory at Leigh, and is proceeding well in a modified form.

One part of the project involves the examination of the fluctuation in level of an acoustic signal passing through the ocean. The fluctuations occur as the result of water inhomogenieties and a knowledge of the nature of these is important to the development of underwater communication and navigation systems. The experimental installation involves a series of hydrophones moored at ranges up to 600 yards from a high frequency acoustic source. All hydrophones are connected by cable to the laboratory buildings on shore. The signal level at each of the hydrophones is recorded on an automatic monitori.y system, and the measurements are repeated periodically to provide data 
on the seasonal effects involved. An associated project involves the measurement of the temperature micro-structure of the water, with which the water inhomogenieties are associated. This work calls for the measurement of the temperature structure at depths from 4 feet to 22 feet over distances of 400 to 600 yards. The sensors are special thermistors spaced on a probe, the whole installation being operated from a ship. Several series of measurements were made at a number of sites and valuable data on turbulence and microstructure obtained. However, this work has had to be deferred until the Navy acquires a replacement vessel.

More difficult technically is the investigation of acoustic phase fluctuations in the received signals. Because of the greater inherent sensitivity of this method, instrumentation for this project is being developed, and it is expected that by January 1970, the phase-fluctuation programme will be proceeding simultaneously with the amplitudefluctuation work. The main practical difficulty arises from the need to have a truly rigid transducer base-line (constant to a small fraction of wavelength, which is a mere $4.3 \mathrm{cms}$ at $35 \mathrm{kHz}$ ). The stability will be provided by large steel tripods, which will be positioned on the seabed in 70 feet of water. The base-line between tripods will be somethin over 150 yards, and the height of the sending and receiving transducers not less than 20 feet above the sea-bed, this height being required for the resolution of the direct and bottom-reflected sound-pulses. It is hoped that by recording in the hottest parts of the summer, adequate temperature-microstructure will exist at this depth (50 feet below the surface) for measurable phase-fluctuation to be encountered.

The final aim is to correlate the nature of the amplitude and phase fluctuations with those that one might predict from measured inhomogenieties within the water, so that ultimately temperature microstructure and fluctuation measurements must proceed concurrently. The research is hence seen to be a long-term one.

\section{Studies of the Magnetosphere}

Until a few years ago physicists believed the earth's magnetic field resembled that of a short bar magnet. It was customary to draw field Iines similar to the lines one sees when iron dust is sprinkled on a sheet of paper above such a magnet. They still choose to represent the earth's magnetic field by field lines, but now draw them very differently. In polar regions the lines rise from the earth and are then swept by the solar wind into long tresses similar to a comet's tail. This tail is known to extend beyond the moon's orbit. In mid and low latitudes the lines leaving the earth return in the opposite hemisphere.

The earth's magnetic field lines behave as a "container" for the charged particles that make up the outer atmosphere, and keep them separate from the solar wind particles. The container defines a region of space around the earth known as the magnetosphere. Occasionally the magnetic field lines get plucked, perhaps by the solar wind, and vibrate like taut strings. This vibration can be observed at ground level with 
sensitive magnetic detectors and by recording these miniscule oscillations at a number of widely separated locations much can be learned about the magnetosphere.

In Auckland we are cooperating with a group at the University of Newcastle by setting up a recording station identical to three they operate in Australia. By timing the fluctuations with very precise crystal clocks it is possible to determine what field line is vibratir We can also learn about the day to day changes in the magnetosphere more conveniently, and much more cheaply, than by making observations from artificial earth satellites. This activity is guided by Dr. J.R. Storey.

\section{Investigations into the Ionosphere}

Extensive ionospheric work in Auckland is carried out by Professor H.A. Whale and Dr. J.E. Titheridge at the Radio Research Centre, and a reference to this is appropriate in this review because of its inter-relationship with those other aspects of the Department's atmospheric physics programme, which have been mentioned already.

The Radio Research Center studies effects of the ionosphere on high frequency radio signals. There are two aspects of this subject receiving attention. First, the changes imposed on a radio signal by the ionosphere are used to determine facts about the physical propertie of the medium; in particular irregularities in electron density are being studied intensively. In this research, which yields considerable information about the general physics of the upper atmosphere, use is made of the signals emitted by satellites.

Closely linked to this main project is the second, which is concerned with the propagation of radio signals over distances long enough to involve ionospheric reflections. The characteristics of these transmissions are being studied in order to understand more fully the detailed mechanism of long distance radio links. This work has therefore a real significance to global radio communication, and like a lot of the geophysical research at Auckland exploits New Zealand' ideal geographical position.

\section{Antartic Research Projects}

Proposals for our participation in the 1969/70 programme have been accepted by the Ross Dependency Research Committee and for the first time the Department will be involved in work in Antarctica. Two separate activities will be undertaken.

The first project is concerned with the measurement of the earth's electric field under the unique conditions prevailing in the "Dry Valley" at Vanda (770 $\left.30^{\prime} \mathrm{S}, 161^{\circ} 31^{\prime} \mathrm{E}\right)$ some seventy miles from scott Base and situated nearly opposite the Japanese station at $70^{\circ} \mathrm{S}, 40^{\circ} \mathrm{E}$. With the American station at the South Pole in between, this new station will provide an invaluable addition to the international network, 
but more important will be the opportunity to carry out measurements of this sort in an environment free from the disturbing meteorological conditions which will affect the other stations.

For the coming summer and throughout 1970 an attempt will be made to establish the diurnal and seasonal trend of the atmospheric potential gradient. Depending upon the success of this year's activity the programme may be extended in subsequent years to include measurements of air currents and ionic conductivity as well, and the introduction of parallel studies at Scott Base. Many problems have to be overcome in operating in the extremes of environment encountered in Antarctica. The specialised equipment developed and built for these measurements is designed to cope with those we have been able to anticipate, but only experience in the field will reveal all the difficulties that will arise.

The second project is concerned with a study of underwater sound in the McMurdo Sound area. The significance of underwater acoustics to all forms of marine investigation has led to its extensive study in most of the oceans of the world. Besides its obvious application in "echo-sounders", and as a target detector in anti-submarine warfare operations, the very small absorption of low frequency sound makes it possible in certain circumstances to detect signals over distances of many thousands of miles. This characteristic has been exploited in mapping acoustically large tracts of uncharted ocean, in detecting and locating underwater volcanism, in detecting and locating the source of the $T$ phase signal produced by earthquake activity, in establishing a connection between the geodetic networks of the major continental masses, and in positioning major hydrological boundaries (such as the Antarctic Convergence) in the seas.

One ocean in which very little underwater acoustic work has been carried out is the Southern Ocean and any data pertinent to it will add significantly to the general subject. On the other hand a great deal of work in underwater acoustics has been done in the Arctic Ocean, and there is considerable interest in a comparison of the general acoustic properties of the Arctic seas and those in the vicinity of Antarctica. The aim of this project is therefore to carry out a series of quantitative acoustic measurements in the McMurdo sound area.

\section{Marine Geophysical and Oceanographic Programmes}

Because of the increasing importance of the oceans and the continental shelf, plans are in hand to develop research programmes in marine geophysics. These plans call for the design and development of a series of instruments such as proton magnetometers, sonobuoys, seismic profiling equipment, tide-swell sensors and various acoustic monitoring systems. Any programme that can be contemplated will however be conditional on the availability of shipping time and finance. 
Field Activities to the North of New Zealand

A number of our geophysical studies could be usefully extended if measurements could be made at a station between New Zealand and the equator. The studies of lightning, the parameters of the atmospheric electric field, geomagnetic micropulsations, and underwater acoustic $T$ phase signals would be enhanced significantly by a field station so placed. Although the practicalities of such a unit have not been examined in any great detail a preliminary survey of sites indicates that Rarotonga would be ideal. Other scientific groups already operate on this island and it appears as if an extension of our work might be feasible at a modest outlay. This matter is being pursued.

\section{The Future}

In planning our future development we will at all times be looking for areas of activity in which we can usefully cooperate with other research organizations active in geophysics, both within New Zealand and overseas. Preliminary discussions with our Department of Geology, interested Government Departments, and certain non-government groups concerned particularly with marine problems, have all pointed to the wide range of topics in which involvement would be profitable both nationally and scientifically. The extent of our involvement will be controlled of course by the speed with which the appropriate facilities and staff can be built up.

\section{Editorial Note}

This article was requested to mark the creation of a chair in Geophysics at the University of Auckland this year. The chair at Auckland is the second in Geophysics to be inaugurated at a New Zealand university, the first being created at Victoria University in 1967. In the interests of completeness, Professor Evison has been asked to contribute a brief article for this issue, covering geophysics at Wellington. His contribution appears under Research News and Notes. 